\title{
AIDS-Related Kaposi Sarcoma T1 (Poor Risk): Extensive Oral Involvement
}

National Cancer Institute

\section{Source}

National Cancer Institute. AIDS-Related Kaposi Sarcoma T1 (Poor Risk): Extensive Oral

Involvement. NCI Thesaurus. Code C134974.

AIDS-related Kaposi sarcoma with lesions that are nodular and/or lesions in roof of the mouth. 